\title{
Does Pemetrexed Work in Targetable, Nonsquamous Non-Small-Cell Lung Cancer? A Narrative Review
}

\author{
Jin-Yuan Shih ${ }^{1,2, * \mathbb{D}}$, Akira Inoue ${ }^{3}$, Rebecca Cheng ${ }^{4}$, Rocio Varea ${ }^{4}$ and Sang-We Kim ${ }^{5}$ \\ 1 Department of Internal Medicine, National Taiwan University Hospital, No. 7 Zhongshan South Road, \\ Zhongzheng District, Taipei City 100, Taiwan \\ 2 Graduate Institute of Clinical Medicine, National Taiwan University, 7 Chung-Shan S. Rd., Taipei 100, Taiwan \\ 3 Department of Palliative Medicine, Tohoku University School of Medicine, 2-1 Seiryo-machi, Aoba-ku, \\ Sendai, Miyagi 980-8575, Japan; akira.inoue.b2@tohoku.ac.jp \\ 4 Eli Lilly and Company, Songshan District, Fuxing North Road 365, Taipei 105, Taiwan; \\ cheng_rebecca@lilly.com (R.C.); varea_menendez_rocio@lilly.com (R.V.) \\ 5 Department of Oncology, Asan Medical Center, 88 Olympic-Ro 43-Gil, Songpa-Gu, Seoul 05505, Korea; \\ swkim@amc.seoul.kr \\ * Correspondence: jyshih@ntu.edu.tw; Tel.: +886-2-2312-3456 (ext. 62905)
}

Received: 14 May 2020; Accepted: 1 September 2020; Published: 17 September 2020

Simple Summary: The chemotherapy agent pemetrexed is currently considered in combination with other therapies for the treatment of advanced nonsquamous non-small-cell lung cancer (NSCLC) in patients negative for gene mutations/rearrangements. The aim of this review was to highlight data from clinical studies with pemetrexed in patients with advanced nonsquamous NSCLC positive for gene mutations/rearrangements. The results of the review suggest that pemetrexed could be a treatment option in patients with advanced nonsquamous NSCLC positive for certain gene mutations/rearrangements.

\begin{abstract}
Pemetrexed is currently mainly considered for the treatment of advanced nonsquamous non-small-cell lung cancer (NSCLC) negative for gene mutations/rearrangements (wild-type disease (WTD)). This narrative review aimed to highlight the role of pemetrexed in the treatment of onco-driven nonsquamous advanced NSCLC by reviewing published clinical studies. For epidermal growth factor receptor (EGFR) mutations, patient survival following first-line pemetrexed-platinum was longer than for WTD. Later-line pemetrexed-based treatment after tyrosine kinase inhibitor (TKI) failure provided greater benefits than non-pemetrexed regimens. First- and later-line pemetrexed-based therapy also provided survival benefits in patients with anaplastic lymphoma kinase (ALK) or ROS proto-oncogene 1 (ROS1) rearrangements. In patients with rearranged during transfection (RET) proto-oncogene rearrangements, survival with pemetrexed was similar to that in ALK- and ROS1-positive patients and longer than that in patients with Kirsten rat sarcoma (KRAS) virus proto-oncogene mutations or WTD, although the available studies were limited. For Erb-b2 receptor tyrosine kinase 2 (ERRB2) mutations, first-line pemetrexed showed outcomes similar to those for EGFR and KRAS alterations. Data on pemetrexed in patients with KRAS mutations or MNNG HOS-transforming (MET) expression were limited. Pemetrexed could be an option for first- and second-line treatment for TKI failure in nonsquamous advanced NSCLC with select targetable driver mutations.
\end{abstract}

Keywords: non-small-cell lung cancer; gain of function mutation; chemotherapy; pemetrexed; progression-free survival 


\section{Introduction}

Non-small-cell lung cancer (NSCLC) accounts for more than $80 \%$ of lung cancer cases [1] and is the leading cause of death from cancer worldwide [2]. Most patients with NSCLC are diagnosed with advanced-stage disease. Within the past decade, several gene mutations and rearrangements in NSCLC have been identified, leading to the development of treatments specifically targeting these molecular alterations (Table 1) [3-6]. It is currently recommended that all patients with nonsquamous NSCLC be tested for certain genetic alterations and the results used to guide treatment [7].

Table 1. Examples of genetic mutations/rearrangements identified in non-small-cell lung cancer (NSCLC) [3-6].

\begin{tabular}{cc}
\hline Genetic Mutation/Rearrangement & \multicolumn{1}{c}{ Examples of Targeted Therapy } \\
\hline EGFR gene mutations & Afatinib, erlotinib, gefitinib, osimertinib \\
\hline ALK gene rearrangements & Alectinib, brigatinib, ceritinib, crizotinib, loratinib \\
\hline RET gene rearrangements & Alectinib, selpercatinib \\
\hline ROS1 rearrangements & Ceritinib, crizotinib, lorlatinib \\
\hline ERBB2 (HER2) mutations & Afatinib, dacomitinib, trastuzumab \\
\hline KRAS mutations & Selumetinib, trametinib \\
\hline BRAF V600E point mutations & Dabrafenib + trametinib \\
\hline PD-L1 expression & Atezolizumab, durvalumab, nivolumab, pembrolizumab \\
\hline MET gene amplifications & Crizotinib \\
\hline MET exon 14 skipping mutations & Cabozantinib, capmatinib, crizotinib \\
\hline NTRK gene fusion & Entrectinib, larotrectinib \\
\hline $\begin{array}{l}\text { Abbreviations: anaplastic lymphoma kinase (ALK); B-Raf proto-oncogene (BRAF); epidermal growth factor receptor } \\
\text { (EGFR); Er-b2 receptor tyrosine kinase 2 (ERBB2); human epidermal growth factor receptor 2 (HER2); Kirsten rat } \\
\text { sarcoma (KRAS) virus proto-oncogene; MNNG HOS-transforming (MET); non-small-cell lung cancer (NSCLC); } \\
\text { neurotrophic tropomyosin receptor kinase (NTRK); programmed death ligand 1 (PD-L1); rearranged during } \\
\text { transfection proto-oncogene (RET); ROS proto-oncogene 1 (ROS1). }\end{array}$
\end{tabular}

Pemetrexed is an antifolate cytotoxic agent with a broad spectrum of antitumor activity. It works by inhibiting multiple folate-dependent enzymes (e.g., thymidylate synthase (TS), glycinamide ribonucleotide formyl transferase, and dihydrofolate reductase), which are essential for cell replication [8]. Pivotal trials of pemetrexed in advanced NSCLC patients have confirmed that, in combination with platinum, pemetrexed provides survival benefit as a first-line treatment [9], as does pemetrexed monotherapy as maintenance or second-line treatment [10-12]. However, the benefits of pemetrexed are confined to patients with nonsquamous histology $[9,11]$ (Supplementary Table S1). TS expression is significantly higher in squamous cell carcinoma than in adenocarcinoma [13], and multiple cell-line studies suggest that high TS expression is associated with reduced sensitivity to pemetrexed [14,15]; although this has not been validated clinically, it may partly explain the superior efficacy of pemetrexed in nonsquamous versus squamous NSCLC [16].

Epidermal growth factor receptor (EGFR) mutations and anaplastic lymphoma kinase (ALK) rearrangements are common in NSCLC and are associated with low levels of tumor cell TS expression [17], suggesting that pemetrexed would be consistently effective against nonsquamous NSCLC with these genomic alterations. Indeed, multiple studies have shown that pemetrexed is effective against nonsquamous NSCLC with targetable driver mutations [18-55].

Guidelines generally recommend pemetrexed in combination with carboplatin or cisplatin and immunotherapy for first-line treatment and as monotherapy for later-line treatment of advanced nonsquamous NSCLC in patients with a performance status of $0 / 1$ who are negative for gene mutations/rearrangements (i.e., with wild-type disease; Supplementary Table S2) [3,4,56,57]. Since 2018, the European Society of Medical Oncology (ESMO) has recommended pemetrexed plus carboplatin and gefitinib as first-line treatments in patients with an EGFR-activating mutation $[4,56]$.

The aim of this narrative review is to highlight the role of pemetrexed in the treatment of targetable nonsquamous advanced NSCLC by reviewing clinical outcomes with the drug in published clinical studies, including systematic reviews, randomized controlled trials, prospective cohort studies, 
post-hoc analyses, and retrospective chart reviews. Relevant studies were identified from nonsystematic searches of PubMed using the search terms "NSCLC" and "pemetrexed" and "EGFR", "ALK", "ROS1", "RET", "ERBB2", "HER2", “KRAS”, or "MET". Searches were performed on 18 February 2019.

\section{EGFR Mutations}

\subsection{First-Line Treatment}

\subsubsection{Pemetrexed-Platinum}

Patients with EGFR mutations treated with first-line pemetrexed-platinum have shown better progression-free survival (PFS) and overall response rate (ORR) than patients with wild-type disease. In a retrospective cohort study of pemetrexed-based chemotherapy in patients with EGFR mutations $(n=69)$ or wild-type disease $(n=89)$, median PFS (8.3 versus 6.7 months, respectively; $p=0.004)$ and ORR (43 versus $21 \%$, respectively; $p=0.039$ ) were significantly greater in EGFR-positive than in wild-type patients for those receiving pemetrexed-platinum (Supplementary Table S3) [18].

The influence of EGFR mutation type on the benefits of pemetrexed therapy is unclear. In a retrospective chart review of 304 patients receiving first-line pemetrexed-cisplatin, median PFS was significantly longer in patients with Leu858Arg point mutations in exon 21 (L858R mutations ( $n=42$ ): 9.4 months) than in those with exon 19 deletions (Del-19 mutations $(\mathrm{n}=36): 5.5$ months; $p=0.049$ ) (Figure 1). However, neither median overall survival (OS) nor ORR differed significantly between the two groups (Supplementary Table S3). In a multivariate analysis, only EGFR mutation status significantly predicted prolonged PFS (hazard ratio (HR) 0.78; $p=0.033$ ) [19].

By contrast, a post-hoc analysis of a phase III open-label study of pemetrexed-carboplatin found no significant difference in median PFS or ORR between patients with L858R ( $\mathrm{n}=51$ ) or Del-19 mutations $(\mathrm{n}=92)$ (Figure 1 and Supplementary Table S3). However, median OS was significantly longer in Del-19-positive (24.5 months) than in L858R-positive patients (18.1 months; $p=0.002)$. In a multivariate analysis, EGFR mutation type significantly predicted longer OS (HR 0.43; $p=0.001)$ [20].

\subsubsection{Pemetrexed-Platinum Versus TKIs}

In studies comparing first-line pemetrexed-platinum or tyrosine kinase inhibitor (TKI) therapy in EGFR-positive patients, median PFS and ORR were greater with TKI therapy. In an open-label study comparing gefitinib $(n=145)$ with pemetrexed-carboplatin induction followed by maintenance pemetrexed $(n=145)$, median PFS and ORR were significantly greater with gefitinib than with chemotherapy (median PFS 8.4 months versus 5.6 months, respectively; HR 0.66; $p=0.001$; ORR 63.5 versus $45.3 \%$, respectively; $p=0.003$ ) (Supplementary Table S3). OS was similar for the two treatments (18.0 versus 22.6 months, respectively; HR 1.28; not significant (NS)) [21].

Similarly, a phase III study (LUX-Lung 3) of 345 EGFR-positive patients (L858R, Del-19 or other) who received afatinib $(n=230)$ or pemetrexed-cisplatin $(n=115)$ showed that afatinib significantly prolonged median PFS versus chemotherapy (11.1 versus 6.9 months, respectively; HR 0.58 ; $p=0.001$ ) [22] (Supplementary Table S3). The difference between afatinib and pemetrexed-cisplatin was even greater for common EGFR mutations (L858R or Del-19 mutations only ( $\mathrm{n}=308$ ): median PFS 13.6 versus 6.9 months, respectively; HR 0.47; $p=0.001)$. ORR was also significantly greater for afatinib versus chemotherapy (56 versus $23 \% ; p=0.001$ ), but OS was similar (28.2 months for both; $p=0.39$ ) [23]. Comparable results were obtained in a subgroup analysis of LUX-Lung 3 Japanese patients [24]. 
A.

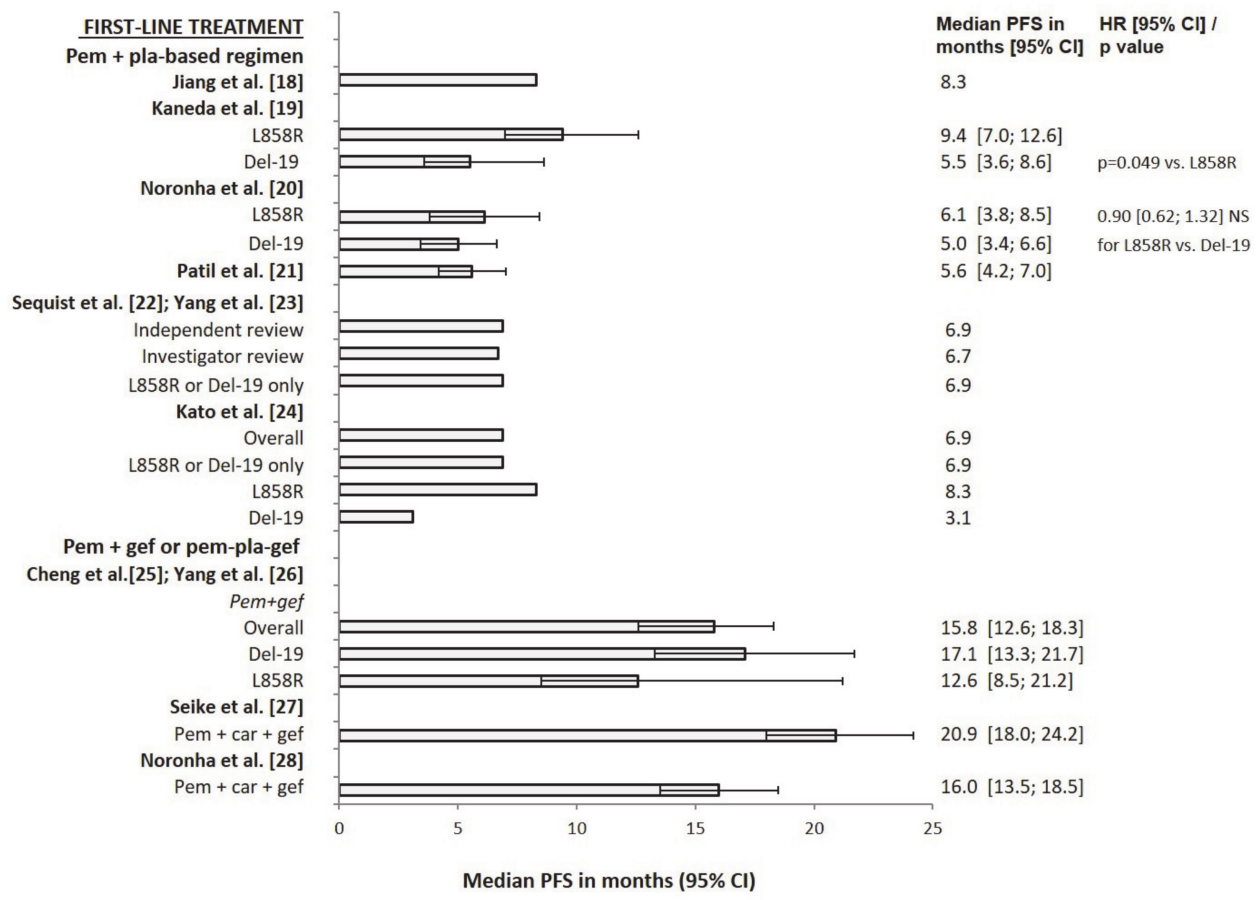

B.

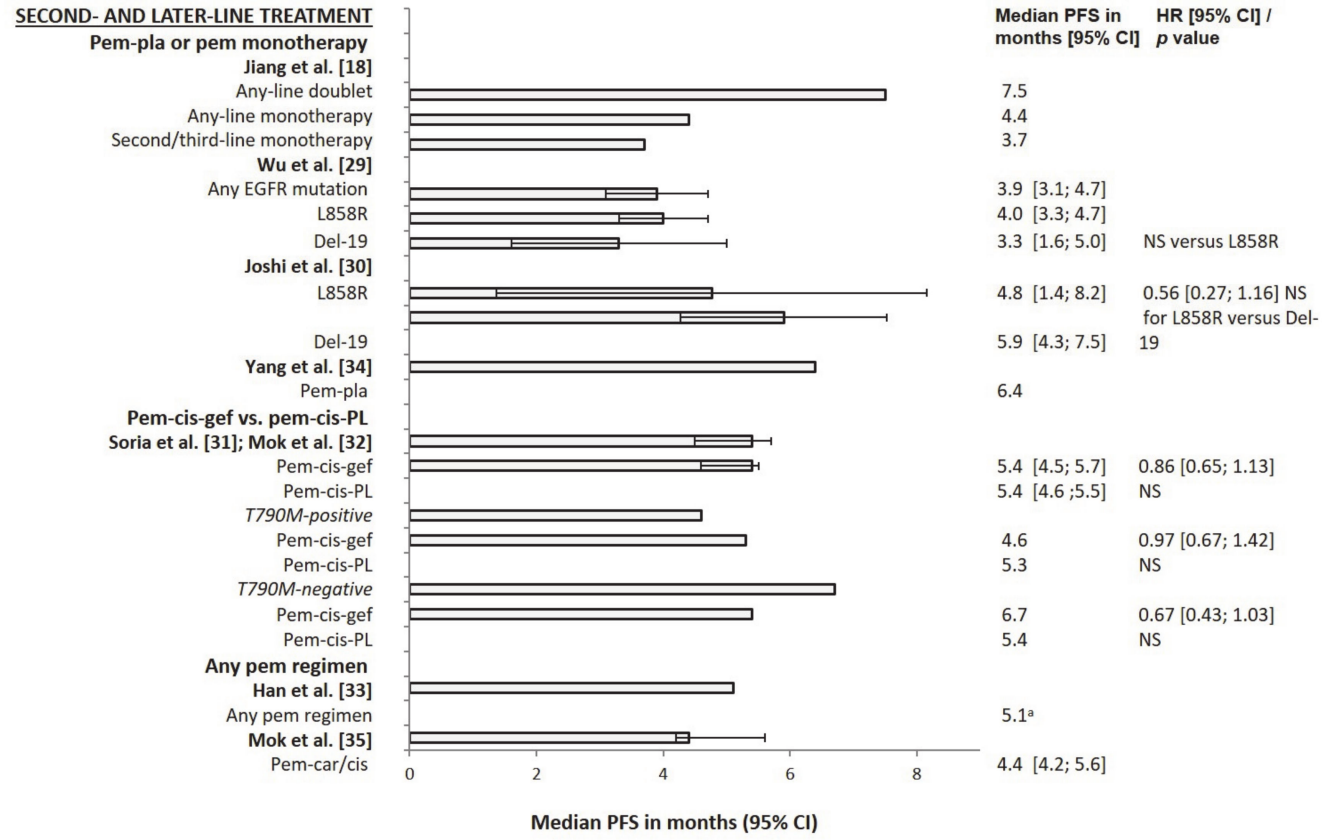

Figure 1. Median progression-free survival (PFS) with (A) first-line and (B) second- and later-line pemetrexed-based treatment in patients with advanced nonsquamous NSCLC and EGFR gene mutations. a Weighted median PFS. Abbreviations: carboplatin (car); cisplatin (cis); confidence interval (CI); EGFR gene exon 19 deletion (Del-19); epidermal growth factor receptor (EGFR); gefitinib (gef); hazard ratio (HR); Leu858Arg point mutation in exon 21 (L858R); not significant (NS); non-small-cell lung cancer (NSCLC); pemetrexed (pem); progression-free survival (PFS); placebo (PL); platinum (pla). 


\subsubsection{Pemetrexed-Gefitinib Versus Gefitinib}

Adding gefitinib to pemetrexed or pemetrexed-platinum improved PFS to a greater extent than treatment with gefitinib alone in first-line settings in EGFR-positive patients. In a phase II open-label study comparing pemetrexed-gefitinib $(n=126)$ with gefitinib monotherapy $(n=65)$, median PFS was significantly prolonged in patients receiving combination therapy (15.8 months) versus those receiving gefitinib alone (10.9 months; adjusted HR 0.68; two-sided $p=0.029)$ (Supplementary Table S3). An analysis according to EGFR mutation type (L858R or Del-19; patient numbers not given) showed a significant improvement in PFS with combination therapy versus gefitinib for both mutation types [25]. ORR ( $80 \%$ versus $74 \%$, respectively) and OS (median 43.4 versus 36.8 months, respectively; HR 0.77; one-sided $p=0.105$ ) did not differ between the two treatments [26]. Similar results were obtained in two phase III open-label studies for median PFS, but OS was significantly longer with combination therapy (Supplementary Table S3) $[27,28]$.

\subsection{Second- and Later-Line Treatment}

\subsubsection{Pemetrexed-Platinum or Pemetrexed Monotherapy}

In the second- or later-line setting, median PFS and ORR were numerically or significantly greater in EGFR-positive than in wild-type patients for pemetrexed-platinum doublet therapy and pemetrexed monotherapy. A previously mentioned retrospective study [18] evaluated all lines of pemetrexed-based chemotherapy in patients with and without EGFR mutations (pemetrexed-platinum: $n=96$; pemetrexed monotherapy: $n=62$ ). For any-line doublet treatment, median PFS was 7.5 versus 6.4 months for EGFR-positive and wild-type patients, respectively (NS) (Supplementary Table S3). A similar pattern was observed for any-line monotherapy (4.4 versus 3.7 months; NS) and second-/third-line monotherapy (3.7 versus 3.2 months; NS). ORR was 27 versus $13 \%$ (NS) for second-line doublet therapy and 13 versus $8 \%$ (NS) for second-/third-line monotherapy.

In a prospective cohort study, median PFS was significantly longer in EGFR-positive ( $\mathrm{n}=93$ : 3.9 months) than in wild-type patients ( $\mathrm{n}=63: 2.3$ months; $p=0.03$ ) for second- or later-line pemetrexed therapy (Supplementary Table S3). However, there was no significant difference between mutation types (Del-19 ( $\mathrm{n}=43)$ : 3.3 months; L858R $(\mathrm{n}=37)$ : 4.0 months; NS) (Figure 1). In a multivariate analysis, EGFR mutation (versus wild-type disease) was significantly associated with PFS (HR 0.68; $p=0.021$ ). ORR was also significantly greater in EGFR-positive than in wild-type patients (12.9 versus $1.6 \% ; p=0.016)$ and did not vary with line of treatment $(8.8 \%, 8.6 \%$, and $7.8 \%$ for second-, third-, and fourth-line therapy, respectively; NS) or type of mutation (14.0\% for Del-19 versus $10.8 \%$ for L858R mutation; NS; $12.5 \%$ for Del-19 or L858R mutation versus $15.4 \%$ for nonclassic mutation; NS). However, OS did not differ significantly between EGFR-positive and wild-type disease (30.8 versus 25.8 months) or between Del-19 and L858R mutations (34.1 versus 29.3 months) [29].

Another study also suggested that median PFS did not differ significantly between Del-19- $(\mathrm{n}=33)$ and L858R-positive patients $(n=22)$ who progressed on first-line gefitinib and received second-line pemetrexed-carboplatin. Median PFS was 5.9 versus 4.8 months for Del-19- and L858R-positive patients, respectively (HR 0.56; NS) (Figure 1 and Supplementary Table S3). However, median OS was significantly longer in Del-19 (11.8 months) than in L858R patients (6.2 months; $p=0.024)$. In a multivariate analysis, EGFR mutation type did not significantly predict OS (HR 0.36; NS). ORR also did not differ significantly between the two mutation groups (L858R: 33.3\%; Del-19: 39.3\%) [30].

\subsubsection{Pemetrexed-Cisplatin-Gefitinib Versus Pemetrexed-Cisplatin-Placebo}

Adding gefitinib to second-line pemetrexed-platinum did not further improve PFS in patients with EGFR-positive advanced NSCLC resistant to first-line gefitinib. In a phase III study (IMPRESS), median PFS was similar for patients receiving pemetrexed-cisplatin-gefitinib $(n=133)$ or pemetrexed-cisplatin-placebo $(n=132)(5.4$ months for both: HR 0.86; NS), as was ORR (31.6 versus 34.1\%, respectively; odds ratio (OR) 0.92; NS) [31]. In a further 
analysis of IMPRESS, OS was significantly longer with pemetrexed-cisplatin-placebo (19.5 versus 13.4 months with pemetrexed-cisplatin-gefitinib; HR 1.44; $p=0.016$ ). An analysis according to T790M mutation status showed that median PFS did not differ significantly between the two treatments for either T790M-positive or T790M-negative patients, whereas OS was significantly longer in the pemetrexed-cisplatin-placebo group in T790M-positive patients (Figure 1 and Supplementary Table S3) [32].

\subsubsection{Pemetrexed Versus Non-Pemetrexed Regimens}

Following TKI failure, the PFS benefit with second-line pemetrexed-based regimens is greater than that with non-pemetrexed-based regimens in EGFR-positive patients. In a systematic review of eight studies involving 640 patients receiving pemetrexed and 97 receiving non-pemetrexed regimens, weighted median PFS was longer for pemetrexed (5.1 months) than for non-pemetrexed regimens (3.2 months) (Supplementary Table S3). Median PFS was significantly longer for pemetrexed versus non-pemetrexed regimens in two of the three studies comparing these regimens (4.2 versus 2.7 months, HR $0.54 ; p=0.009$ in one study; 6.4 versus 4.1 months, HR $0.47 ; p=0.01$ in the other study), but not in the third (4.7 versus 3.3 months (NS)) [33].

Similar results were obtained for weighted median OS and weighted ORR. Weighted OS was longer for pemetrexed (15.9 months) than for non-pemetrexed regimens (11.1 months), with numerical but nonsignificant differences reported in the three studies comparing these regimens (15.1 versus 11.0 months, HR 0.92; 19.2 versus 14.1 months, $0.50 ; 15.1$ versus 8.1 months; all $p$-values NS) (Supplementary Table S3). Weighted ORR was 30.2\% for pemetrexed and $18.3 \%$ for non-pemetrexed regimens. Again, the differences reported in the two studies comparing these regimens were numerically but not significantly higher with pemetrexed versus non-pemetrexed regimens (32.4 versus $17.4 \%$ and 26.0 versus $20.0 \%$, both $p$-values NS).

A retrospective cohort study evaluated second-line therapies in patients resistant to first-line gefitinib. Treatments included erlotinib monotherapy and platinum-based doublet therapy with pemetrexed, gemcitabine, vinorelbine, or taxanes. Median PFS was significantly longer for pemetrexed-platinum $(n=34)$ than for non-pemetrexed platinum-based doublet therapy $(n=26$; 6.4 versus 4.1 months, $p=0.008$; HR 0.42; 95\% CI 0.23-0.77) (Supplementary Table S3). OS and ORR were numerically but not significantly greater with pemetrexed-platinum than with non-pemetrexed-based therapy (19.2 versus 14.1 months and 24 versus 12\%, respectively; NS for both) [34].

\subsubsection{Pemetrexed-Platinum Versus Osimertinib}

In a phase III open-label study (AURA3) median PFS and ORR were significantly greater with osimertinib than with pemetrexed-platinum in patients with EGFR-T790M-positive NSCLC. Among 419 EGFR-T790M-positive patients with disease progression after first-line TKI therapy, median PFS was 10.1 months with osimertinib versus 4.4 months with pemetrexed-platinum (HR 0.30; $p<0.001$ ). ORR was 71 versus 31\% (OR 5.39; $p<0.001$ ) (Supplementary Table S3). OS data were immature and therefore not presented [35].

\section{ALK Rearrangements}

\subsection{First-Line Treatment}

\subsubsection{Pemetrexed-Platinum}

Studies have suggested that pemetrexed-platinum doublet therapy is effective in the first-line treatment of ALK-positive NSCLC. A retrospective chart review of 52 ALK-positive patients receiving first-line pemetrexed-platinum (two patients received single-agent pemetrexed) revealed a median PFS of 9.5 months, median OS of 20.7 months and an ORR of 34.6\% [36] (Figure 2 and Supplementary Table S4). Another retrospective chart review of any-line pemetrexed in 121 ALK-positive and 266 
ALK-negative patients (79 ALK-negative patients had Kirsten rat sarcoma (KRAS) virus proto-oncogene mutations and 187 had wild-type KRAS) showed that, for first-line pemetrexed-platinum, median PFS was significantly longer (8.5 months) in ALK-positive $(\mathrm{n}=56)$ than in ALK-negative KRAS-positive ( $\mathrm{n}=44 ; 4.1$ months; $p=0.004)$ and ALK-negative KRAS-negative patients $(\mathrm{n}=104 ; 5.4$ months; $p=0.018$ ) [37] (Supplementary Table S4).

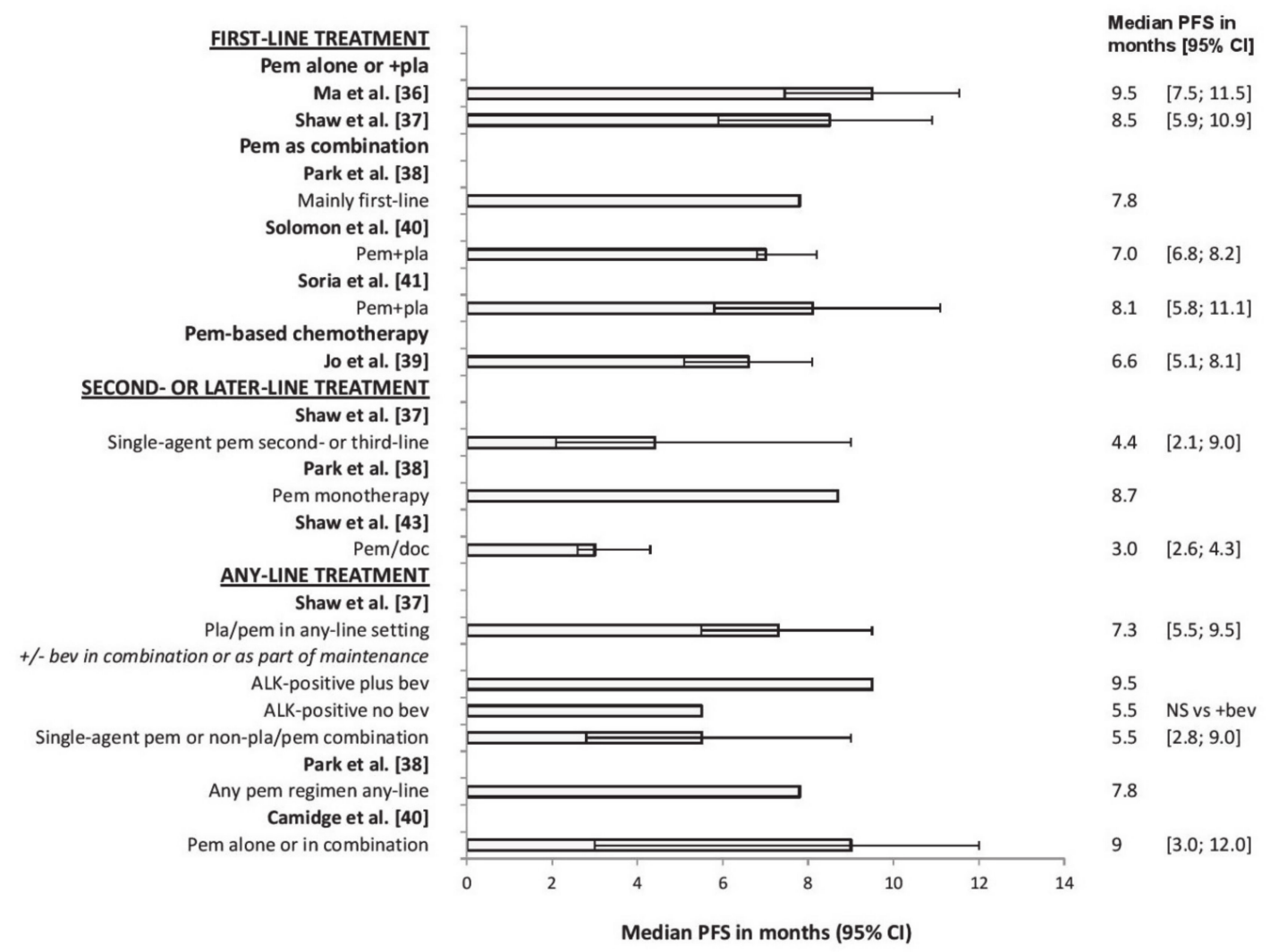

Figure 2. Median PFS with pemetrexed-based treatment in patients with advanced nonsquamous NSCLC and ALK rearrangements. Abbreviations: anaplastic lymphoma kinase (ALK); bevacizumab (bev); carboplatin (car); cisplatin (cis); confidence interval (CI); non-small-cell lung cancer (NSCLC); not significant (NS); pemetrexed (pem); progression-free survival (PFS); placebo (PL); platinum (pla); docetaxel (doc); hazard ratio (HR).

However, a cohort study suggested no difference in PFS or ORR between ALK-positive and wild-type patients, or those with EGFR or KRAS mutations, after pemetrexed generally given as first-line combination therapy. For patients with ALK rearrangements $(\mathrm{n}=52)$, EGFR mutations $(\mathrm{n}=188)$, KRAS mutations $(\mathrm{n}=34)$ or wild-type disease $(\mathrm{n}=168)$, median PFS was 7.8, 5.3, 4.6, and 4.3 months, respectively; ORR was $22.2 \%, 20.0 \%, 11.1 \%$, and $33.3 \%$, respectively [38].

\subsubsection{Pemetrexed Versus Non-Pemetrexed Regimens}

In a retrospective cohort study of ALK-positive patients receiving first-line pemetrexed-based chemotherapy $(n=48)$ or other cytotoxic chemotherapy regimens $(n=78)$, median PFS was significantly longer with pemetrexed than with non-pemetrexed regimens (6.6 versus 3.8 months; $p=0.001$ ) (Supplementary Table S4). In a multivariate analysis, only non-pemetrexed treatment significantly predicted poorer PFS (HR 1.91; $p=0.002)$. ORR $(44.7$ versus $14.3 \%$; $p<0.001)$, but not OS (66.5 versus 49.2 months (NS)), was also significantly greater with pemetrexed than with non-pemetrexed regimens [39]. 


\subsubsection{Pemetrexed-Platinum Versus TKIs}

Although first-line pemetrexed-platinum therapy provides survival benefit in ALK-positive patients, survival outcomes are longer with TKIs (e.g., crizotinib and ceritinib). In a phase III open-label study (PROFILE 1014) of 343 ALK-positive patients receiving first-line pemetrexed-cisplatin/carboplatin ( $\mathrm{n}=171)$, or crizotinib ( $\mathrm{n}=172)$, median PFS was 7.0 months with pemetrexed-based chemotherapy versus 10.9 months with crizotinib (HR 0.45; $p<0.0001$ ). Similarly, ORR was $45 \%$ versus $74 \%(p<0.001)$. At the time of analysis, there was no significant difference in OS or the probability of 1-year survival (Supplementary Table S4) [40].

In another phase III open-label study (ASCEND-4) of 376 ALK-positive patients receiving first-line pemetrexed-cisplatin/carboplatin then maintenance pemetrexed $(n=187)$, or ceritinib $(n=189)$, median PFS was 8.1 months with chemotherapy and 16.6 months with ceritinib (HR $0.55 ; p<0.00001$ ). Median OS (immature data) was 26.2 months versus not reached (HR 0.73; $p=0.056$ ). Corresponding values for ORR were 26.7 versus $72.5 \%$ [41].

\subsection{Second- and Later-Line Treatment}

Pemetrexed monotherapy was effective for second- or later-line treatment of ALK-positive NSCLC. Results conflicted for whether pemetrexed was more effective in ALK-positive patients than in those with wild-type disease or other types of mutation but, overall, they favored greater efficacy in ALK-positive patients. In a cohort study of ALK-positive $(n=15)$, EGFR-positive $(n=43)$, or wild-type patients $(n=37)$ receiving second- or later-line pemetrexed monotherapy, ORR was significantly higher in ALK-positive (46.7\%) than in EGFR-positive $(4.7 \%)$ or wild-type patients $(16.2 \% ; p=0.001)$ (Supplementary Table S4). For second-line pemetrexed only ( $\mathrm{n}=38$ ), ORR was numerically but not significantly higher in ALK-positive than in EGFR-positive and wild-type patients (50.0\%, 0\%, and $19.2 \%$, respectively); for third- or later-line treatment $(n=57)$, ORR was significantly higher in ALK-positive patients $(44.4 \%, 5.4 \%$, and 9.1\%, respectively; $p=0.006)$. In a multivariate analysis, only ALK positivity significantly predicted a favorable ORR (HR 0.07; $p=0.001$ ) [42].

In a previously mentioned study [37] in 121 ALK-positive patients and 266 ALK-negative EGFR wild-type patients, including 79 with KRAS mutations and 187 with wild-type KRAS, in which patients received any-line pemetrexed-based chemotherapy, median PFS did not differ significantly between ALK-positive (4.4 months), ALK-negative KRAS-positive (7.8 months), and ALK-negative KRAS-negative patients (3.8 months) receiving second- or third-line pemetrexed monotherapy $(n=31)$ (Supplementary Table S4).

Another previously mentioned cohort study [38] of ALK-positive $(n=52)$, EGFR-positive $(n=188)$, KRAS-positive $(n=34)$, and wild-type $(n=168)$ patients receiving any-line pemetrexed-based therapy, revealed significantly longer median PFS in ALK-positive patients than in all other mutation groups $(8.7,2.0,1.6$, and 1.9 months, respectively; $p<0.001)$ (Supplementary Table S4) for those receiving mainly second- or later-line pemetrexed monotherapy. A similar pattern was seen with ORR $(29.0 \%$, $8.4 \%, 8.7 \%$, and $11.8 \%$, respectively; $p=0.013$ ).

\section{Pemetrexed-Docetaxel Versus TKIs}

In a phase III, open-label crossover study of 347 ALK-positive patients who progressed on one prior first-line platinum-based regimen, second-line crizotinib $(n=173)$ produced greater benefit than pemetrexed or docetaxel $(\mathrm{n}=174)$. Median PFS was 3.0 months with chemotherapy and 7.7 months with crizotinib (HR for disease progression or death with crizotinib was 0.49 versus chemotherapy, 0.59 versus pemetrexed, and 0.30 versus docetaxel; $p<0.001$ for all comparisons) (Supplementary Table S4). ORR was 20\% with chemotherapy and 65\% with crizotinib (intention-to-treat (ITT) population; $p<0.001$ ), and $29 \%, 7 \%$, and $66 \%$ with pemetrexed, docetaxel, and crizotinib, respectively (as-treated population; $p<0.001$ for crizotinib versus both). Median OS was similar for 
chemotherapy and crizotinib (22.8 versus 20.3 months, respectively; HR 1.02; NS). This lack of survival benefit with crizotinib probably reflected the confounding effects of crossover [43].

\subsection{Any-Line Treatment}

Several studies compared any-line pemetrexed (combination or monotherapy) between patients with ALK rearrangements, EGFR or KRAS mutations, or wild-type disease. Results generally showed that any-line pemetrexed improved PFS and ORR in ALK-positive patients versus patients with other mutation types or wild-type disease.

In a previously mentioned study [37] of ALK-positive $(n=121)$ and ALK-negative EGFR wild-type patients $(n=266)$, including 79 with KRAS mutations and 187 with wild-type KRAS, patients received any-line pemetrexed-based chemotherapy as either combination or monotherapy. For patients receiving pemetrexed-platinum in any setting, median PFS was significantly longer in ALK-positive (7.3 months) than in ALK-negative KRAS-positive patients (4.5 months; $p=0.042)$ but was similar to that in ALK-negative KRAS-wild-type patients (5.9 months) (Supplementary Table S4). ALK-positive patients showed a trend toward improved median PFS when receiving bevacizumab as part of either the pemetrexed-platinum combination or maintenance therapy ( 9.5 versus 5.5 months without bevacizumab; $p=0.087$ ). For patients receiving pemetrexed monotherapy or non-platinum-pemetrexed, median PFS was similar for ALK-positive (5.5 months), ALK-negative KRAS-positive (7.8 months), and ALK-negative KRAS-negative patients (3.9 months).

In a previously mentioned cohort study [38] of ALK-positive $(n=52)$, EGFR-positive $(n=188)$, KRAS-positive $(\mathrm{n}=34)$, and wild-type $(\mathrm{n}=168)$ patients receiving any-line pemetrexed as combination (mainly first-line) or monotherapy (mainly later-line), median PFS was significantly longer in ALK-positive (7.8 months) than in EGFR-positive (2.5 months), KRAS-positive (2.3 months), or wild-type patients $(2.9$ months) $(p<0.001)$ for all pemetrexed regimens combined (Supplementary Table S4). In a multivariate analysis, PFS was longer in ALK-positive than in other patients (HR 0.39 versus EGFR mutations, 0.42 versus KRAS mutations, 0.43 versus wild-type disease; $p<0.001$ for all comparisons). ORR was also significantly higher in ALK-positive (26.9\%) than in EGFR-positive (12.8\%), KRAS-positive $(8.8 \%)$, and wild-type $(18.6 \% ; p=0.046)$ patients for all pemetrexed regimens combined.

In a retrospective review of ALK-positive $(n=19)$, EGFR-positive $(n=12)$, KRAS-positive $(n=21)$ or triple-negative $(n=37)$ patients who received any-line pemetrexed as combination or monotherapy, median PFS was longer for ALK-positive (9 months) than for EGFR-positive (5.5 months), KRAS-positive (7 months), or triple-negative patients (4 months) (Supplementary Table S4). In a multivariate analysis, only ALK positivity predicted prolonged PFS on pemetrexed (HR $0.36 ; p=0.005$ ). Line of therapy predicted worse PFS on pemetrexed (HR 1.57; $p=0.022$ ). ORR was $42 \%$ for ALK-positive, $30 \%$ for EGFR-positive, $37 \%$ for KRAS-positive, and $14 \%$ for triple-negative patients [44].

\section{ROS1 Rearrangements}

Patients with ROS proto-oncogene1 (ROS1) rearrangement may benefit from pemetrexed-based treatment, with PFS similar to that in ALK-positive patients and longer than that in patients with echinoderm microtubule-associated protein-like 4-ALK (EML4-ALK), EGFR or KRAS mutations, or wild-type disease (Supplementary Table S5). In a cohort study comparing pemetrexed-based first-line therapy in ROS1-positive $(n=12)$, ALK-positive $(n=27)$, EGFR-positive $(n=34)$, KRAS-positive $(n=22)$ or quadruple-negative patients $(n=27)$, median PFS in ROS1-positive patients was similar to that in ALK-positive patients ( 6.8 and 6.7 months, respectively) and longer than that in EGFR-positive, KRAS-positive, or quadruple-negative patients (5.2, 4.2, and 4.5 months, respectively; among-group difference $p=0.003$ ) [45].

A retrospective chart review of ROS1-positive $(n=5)$, ALK-positive $(n=13)$, and ROS1/ ALK-negative patients $(n=144)$ receiving second- or third-line pemetrexed following first-line platinum-based therapy showed longer median PFS in ROS1-positive (not reached) than in ALK-positive (11.5 months) and ROS1/ALK-negative patients (3.3 months; $p=0.008$ for ROS1-positive versus 
ROS1/ALK-negative patients) (Supplementary Table S5). ORR showed a similar pattern $(60.0 \%$ for ROS1-positive versus 33.3\% for ALK-positive (NS) and 8.5\% for ROS1/ALK-negative patients $(p=0.01$ for ROS1-positive versus ROS1/ALK-negative patients)). In Cox regression analysis, ROS1 rearrangement strongly predicted longer median PFS (HR 0.09; $p=0.02$ ) [46].

In a retrospective cohort study of patients with ROS1 $(\mathrm{n}=19)$, EGFR $(\mathrm{n}=102)$, EML4-ALK $(n=32)$, or KRAS $(n=3)$ mutations/rearrangements, or quadruple-negative status $(n=97)$ who received any-line pemetrexed, as either combination or monotherapy, median PFS was longer in ROS1-positive (7.5 months) (Figure 3) than in EGFR-positive (3.7 months), EML4-ALK-positive (5.4 months), or quadruple-negative patients (4.1 months) (log-rank $p=0.003$ for ROS1-positive versus other groups) (Supplementary Table S5). In a multivariate analysis, ROS1 positivity predicted longer PFS (HR 0.44; $p=0.005$ ). ORR was significantly greater for ROS1-positive than for EGFR, EML4-ALK, and quadruple-negative patients $(57.9 \%, 25.5 \%, 28.1 \%$, and $24.7 \%$, respectively; $p=0.026$ for ROS1-positive versus other groups) (Supplementary Table S5) [47].

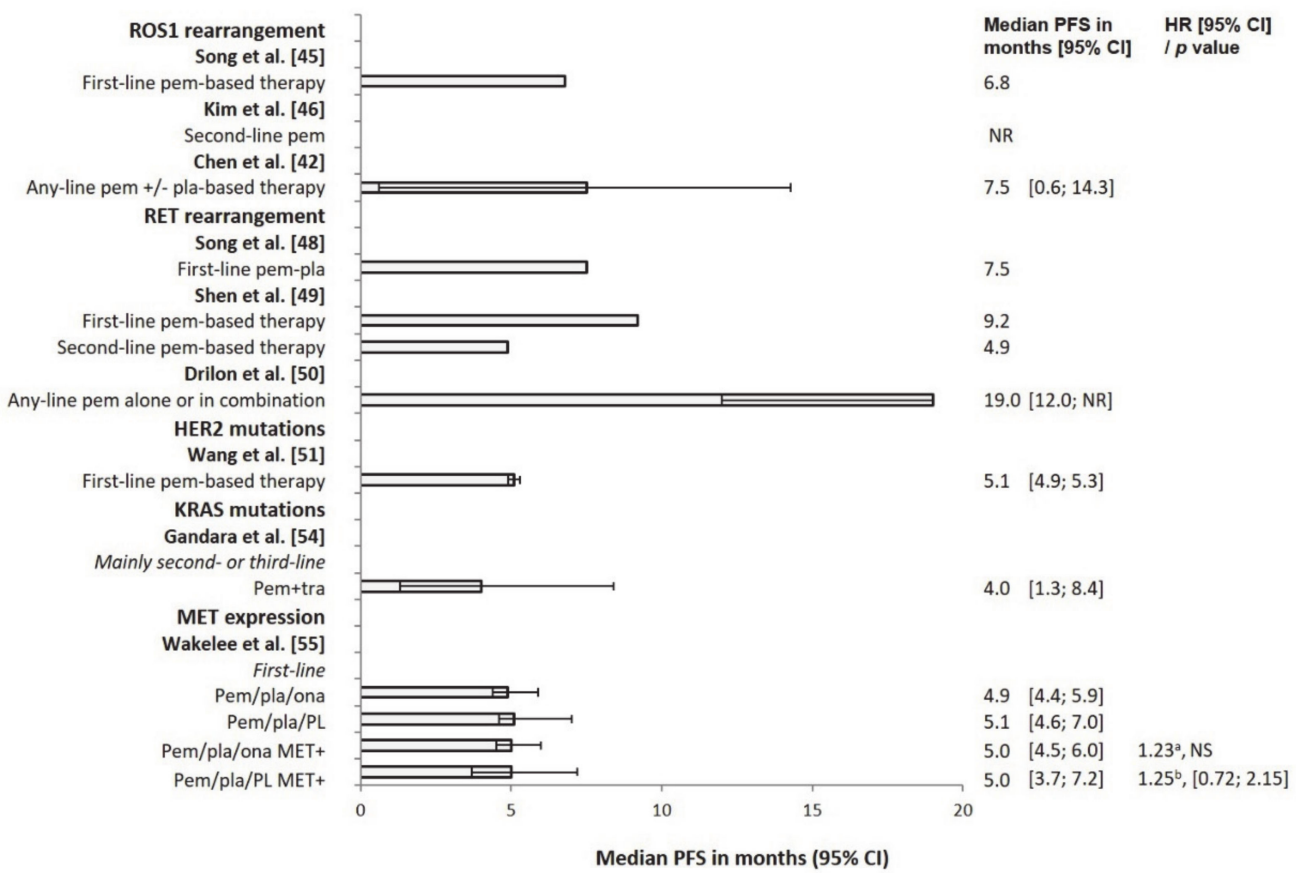

Figure 3. Median PFS with pemetrexed-based treatment in patients with advanced nonsquamous NSCLC and ROS1 or RET rearrangements, or HER2 or KRAS mutations, or MET expression. a Stratified HR. ${ }^{b}$ Unstratified HR. Abbreviations: confidence interval (CI); human epidermal growth factor receptor 2 (HER2); Kirsten rat sarcoma virus proto-oncogene (KRAS); MNNG HOS-transforming (MET); non-small-cell lung cancer (NSCLC); neurotrophic tropomyosin receptor kinase (NTRK); programmed death ligand 1 (PD-L1); rearranged during transfection proto-oncogene (RET); ROS proto-oncogene 1 (ROS1); hazard ratio (HR); not reached (NR); not significant (NS); onartuzumab (ona); pemetrexed (pem); progression-free survival (PFS); placebo (PL); platinum (pla); rearranged during transfection proto-oncogene (RET); trametinib (tra).

\section{RET Rearrangements}

Patients with rearranged during transfection (RET) proto-oncogene rearrangement may benefit from pemetrexed-based treatment, with median PFS similar to that in patients with ROS1 or ALK rearrangements and longer than in patients treated with other chemotherapy regimens and patients with KRAS-positive or wild-type disease. In a cohort study of four RET-positive and 64 RET-negative patients receiving first-line pemetrexed-platinum, median PFS was significantly longer in RET-positive 
than in RET-negative patients (7.5 versus 5.0 months; $p=0.026)$ (Supplementary Table S5). However, OS did not differ significantly between the two groups (58.1 versus 52.0 months) [48].

A retrospective review of 62 RET-positive patients showed that, for patients receiving first-line therapy $(\mathrm{n}=40)$, median PFS was significantly longer in those treated with pemetrexed-based regimens (9.2 months) than in those treated with other chemotherapy regimens (paclitaxel-platinum or gemcitabine-platinum: 5.2 months; $p=0.007$ ) (Supplementary Table S5). Corresponding values for second-line treatment $(\mathrm{n}=28)$ were 4.9 and 2.8 months, respectively $(p=0.049)$. There was a trend towards longer OS in the pemetrexed-based treatment group (35.2 versus 22.6 months; $p=0.052$ ) [49].

Another retrospective review of patients with a RET $(n=18)$, ROS1 $(n=10)$, or ALK $(n=36)$ rearrangement, or a KRAS mutation $(\mathrm{n}=40)$ receiving any-line pemetrexed as combination or monotherapy revealed that median PFS was comparable for RET- (19 months), ROS1- (23 months) and ALK-positive patients (19 months) and significantly shorter in KRAS-positive patients (6 months; $p=0.005$ versus RET, $p=0.002$ versus ROS1, and $p<0.001$ versus ALK). Median OS and ORR showed similar patterns (Supplementary Table S5) [50].

\section{HER2 Mutations}

Results with pemetrexed-based therapy in patients with Erb-b2 receptor tyrosine kinase (ERBB2, also known as human epidermal growth factor receptor 2 (HER2)) mutations are only available from observational studies, but have been favorable. A cohort study suggested that PFS and ORR in patients with HER2 mutations receiving first-line pemetrexed-based treatment were similar to those in patients with EGFR or KRAS mutations, but inferior to those in patients with ALK/ROS1 rearrangements. In the study, median PFS was 5.1 months in patients with HER2 mutations versus 6.5, 9.2, and 5.0 months in patients with EGFR, ALK/ROS1, and KRAS mutations, respectively. ORR was 36.0\%, 33.8\%, 41.3\%, and $35.0 \%$, respectively (Supplementary Table S5) [51].

Numerically longer treatment duration (indicating patients did not progress as quickly) was observed with pemetrexed-based first-line therapy than with other therapies in HER2-positive patients. However, results with later-line treatment have been conflicting. In a retrospective chart review of 38 patients with HER2 mutations receiving first- or later-line chemotherapy or HER2-targeted therapy, median duration of first-line treatment was longer with pemetrexed-based regimens (8.8 months (18 treatments)) than with taxane-based (4.0 months (five treatments)) or gemcitabine-based regimens (4.4 months (three treatments)) or HER2-targeted therapy (5.2 months (nine treatments)) (Supplementary Table S5). However, the differences were not statistically significant, and this pattern was not observed with later-line treatment (3.9, 4.0, 2.3, and 1.8 months, respectively) [52].

Similarly, an analysis of treatment duration in 29 patients with HER2 mutations receiving various first- or later-line treatment regimens showed that median duration of treatment was longer with first-line pemetrexed-based regimens (6.3 months) than with taxane- (5.3 months), gemcitabine(4.9 months), or navelbine-based regimens ( 2.2 months) or gefitinib/erlotinib (2.1 months). A similar pattern was observed for duration of later-line treatment (6.0, 3.2, 5.4, 3.3, and 2.1 months, respectively) (Supplementary Table S5). In a multivariate analysis of the total study population $(\mathrm{n}=591$ with HER2, EGFR, ALK, or KRAS mutations), pemetrexed significantly predicted favorable OS (HR 0.48; $p<0.001)$ [53].

\section{KRAS Mutations}

Patients with a KRAS mutation may benefit from pemetrexed-based treatment, since the ORR with such treatment in one study exceeded that in patients with wild-type disease. However, this benefit was not reflected in median PFS. In this phase Ib open-label study comparing any-line pemetrexed-trametinib with docetaxel-trametinib in KRAS-positive $(n=48)$ or KRAS-negative/KRAS status unknown patients $(n=41)$, median PFS was shorter in KRAS-positive than in KRAS-negative/KRAS status unknown patients for pemetrexed-trametinib (4.0 versus 5.8 months; $\mathrm{n}=23$ and $\mathrm{n}=19$ for KRAS-negative/KRAS status unknown, respectively) and docetaxel-trametinib 
(3.4 versus 4.2 months; $\mathrm{n}=25$ and $\mathrm{n}=22$, respectively) (Supplementary Table S5). By contrast, ORR was numerically greater in KRAS-positive than in KRAS-negative/KRAS status unknown patients with both treatment regimens (17 versus 11\% for pemetrexed-trametinib, 24 versus $18 \%$ for docetaxel-trametinib) [54].

\section{MET Expression}

In the control arm of a randomized study (GO27821), the survival benefit with pemetrexed-based therapy in patients with MNNG HOS transforming (MET) gene expression was similar to that in the overall NSCLC patient population for PFS but poorer for OS. Median PFS in MET-positive patients receiving first-line pemetrexed-platinum-placebo $(n=37)$ was 5.0 months, corresponding to that in the pemetrexed-platinum-placebo ITT population ( $\mathrm{n}=61: 5.1$ months) (Figure 3 and Supplementary Table S5) [55].

\section{Future Perspectives}

TKIs are the current standard of care for advanced NSCLC with targetable driver mutations. Since the addition of pemetrexed to gefitinib improves outcomes in patients with newly diagnosed EGFR-positive NSCLC $[25,26]$, it is feasible that the addition of pemetrexed to the third-generation TKI osimertinib could also improve outcomes in such patients. A phase III open-label randomized study of first-line osimertinib with or without pemetrexed-platinum in approximately 556 patients with EGFR-positive advanced NSCLC (FLAURA2) is currently underway [58]. The study is expected to be completed in March 2026.

However, patients eventually develop resistance to TKIs [59,60] and treatment options after the failure of such therapy are limited. Immune checkpoint inhibitors that block programmed death-1/programmed death ligand 1 (PD-1/PD-L1), such as atezolizumab, nivolumab, and pembrolizumab, have recently been approved and recommended for the first- and second-line treatment of NSCLC without driver mutations [3,4,7,56]. However, inconsistent results have been obtained with these agents when given as monotherapy for second-line treatment in patients with EGFR-positive disease [61-64], and it therefore remains to be determined whether they are appropriate for use in patients with driver mutations. Combining immune checkpoint inhibitors with pemetrexed could improve outcomes [65], providing a potential therapeutic option following the development of TKI resistance. Indeed, several ongoing clinical studies are assessing the benefits of such combination treatment in patients with EGFR-positive advanced nonsquamous NSCLC who progressed after TKI therapy [66-68]. The studies CheckMate 722 [66] and WJOG8515L [67] are investigating nivolumab in combination with pemetrexed and a platinum, the KEYNOTE-789 study [68] is evaluating pembrolizumab in combination with pemetrexed and a platinum, and study NCT03924050 is evaluating toripalimab in combination with pemetrexed and a platinum. The results of these studies are awaited.

\section{Conclusions}

The identification of molecular mutations and rearrangements in NSCLC has been accompanied by the development of therapies targeting these alterations. However, cytotoxic agents such as pemetrexed still have an antitumor role in the treatment algorithm. Although guidelines generally recommend pemetrexed for first- and later-line treatment of advanced nonsquamous NSCLC in patients negative for gene mutations/rearrangements (i.e., with wild-type disease), this nonsystematic literature review suggests that survival outcomes with pemetrexed in patients with gene mutations/rearrangements are comparable to those in unselected patients. However, prospective clinical studies will be needed to confirm these findings.

Pemetrexed-containing regimens have been tested in first-line settings and as a sequential option following TKI failure in NSCLC patients with targetable driver mutations. In patients with EGFR, ALK, or ROS1 mutations, pemetrexed-based treatment improves PFS to a greater extent than in patients with 
wild-type disease, even after failure of TKI therapy. Limited data are available for patients with RET rearrangements or those with HER2 or KRAS mutations or MET expression. The few available studies suggest that in patients with RET rearrangements, the survival benefit with pemetrexed is similar to that in ALK- and ROS1-positive patients and longer than that in patients with KRAS mutations or wild-type disease. In patients with HER2 mutations, first-line pemetrexed-based therapy produces outcomes similar to those observed in patients with EGFR and KRAS alterations but shorter survival than in patients with ALK or ROS1 rearrangements. The ORR with pemetrexed-based therapy is greater in patients with KRAS mutations than in those with wild-type disease, but this benefit is not reflected in PFS. In patients expressing MET, pemetrexed-based therapy produces similar PFS to that in the overall NSCLC patient population, but shorter OS.

Possible reasons for differences in survival outcomes with pemetrexed across the different mutation types include different study methodology (some analyses lacked the power to assess certain endpoints), that a benefit in PFS may not translate into a benefit in OS due to the lack of post-discontinuation treatment options for some molecular alterations, differences in the patient populations studied due to differences in the methods used to identify molecular alterations, and that some molecular alterations may indicate a poor prognosis.

We suggest that chemotherapy with pemetrexed-based regimens still has a role in the treatment algorithm for patients with advanced nonsquamous NSCLC with targetable driver mutations and should not be overlooked as a treatment option in this era of targeted therapy.

Supplementary Materials: The following are available online at http://www.mdpi.com/2072-6694/12/9/2658/s1, Table S1: Summary of results from pivotal trials of pemetrexed in unselected patients with NSCLC, Table S2: Guideline recommendations for the use of pemetrexed in nonsquamous NSCLC, Table S3: Summary of results from studies of pemetrexed in patients with advanced nonsquamous NSCLC and EGFR gene mutations, Table S4: Summary of results from studies of pemetrexed in patients with advanced nonsquamous NSCLC and ALK rearrangements, Table S5: Summary of results from studies of pemetrexed in patients with advanced nonsquamous NSCLC and ROS or RET gene rearrangements, HER2 or KRAS mutations, or MET expression.

Author Contributions: Conceptualization, J.-Y.S., A.I., R.C. and R.V.; data curation, J.-Y.S., S.-W.K., R.C. and R.V.; writing-original draft preparation; writing—review and editing, J.-Y.S., A.I., S.-W.K., R.C. and R.V. All authors have read and agreed to the published version of the manuscript.

Funding: The development of this manuscript was funded by Eli Lilly and Company.

Acknowledgments: Medical writing services were provided by Sue Chambers and Gill Gummer (Rx Communications, Mold, UK), funded by Eli Lilly and Company.

Conflicts of Interest: Jin-Yuan Shih has served as an advisory board member for and has received speaker honoraria from AbbVie, AstraZeneca, Boehringer Ingelheim, Bristol-Myers Squibb, Chugai, Eli Lilly, Merck Sharp \& Dohme, Novartis, Ono Pharmaceutical, and Roche and has received expenses for travel and accommodation from Boehringer Ingelheim, Bristol-Myers Squibb, Merck Sharp \& Dohme, Pfizer, and Roche. Akira Inoue reports personal fees from Eli Lilly, during the conduct of the study. Rebecca Cheng and Rocio Varea are employees and shareholders of Eli Lilly and Company. Sang-We Kim declares no conflicts of interest. The funding sponsor played in a role in the design of the manuscript; in the collection and interpretation of data; in the writing of the manuscript; and in the decision to submit the manuscript for publication.

\section{References}

1. Noone, A.M.; Howlader, N.; Krapcho, M.; Miller, D.; Brest, A.; Yu, M.; Ruhl, J.; Tatalovich, Z.; Mariotto, A.; Lewis, D.R.; et al. SEER Cancer Statistics Review, 1975-2015; National Cancer Institute: Bethesda, MD, USA, 2018. Available online: https://seer.cancer.gov/csr/1975_2015/ (accessed on 12 February 2019).

2. International Agency for Research on Cancer. World Health Organization. Cancer Fact Sheet. Lung Cancer. 2018. Available online: http://gco.iarc.fr/today/data/factsheets/cancers/15-Lung-fact-sheet.pdf (accessed on 14 February 2019).

3. National Comprehensive Cancer Network (NCCN). NCCN Clinical Practice Guidelines in Oncology (NCCN Guidelines). Non-Small Cell Lung Cancer. Version 3.2019. 18 January 2019. Available online: https://www.nccn.org/professionals/physician_gls/default.aspx (accessed on 14 February 2019). 
4. Planchard, D.; Popat, S.; Kerr, K.; Novello, S.; Smit, E.F.; Faivre-Finn, C.; Mok, T.S.; Reck, M.; van Schil, P.E.; Hellmann, M.D.; et al. Metastatic non-small cell lung cancer: ESMO clinical practice guidelines for diagnosis, treatment and follow-up. Ann. Oncol. 2018, 29 (Suppl. 4), iv92-iv237. [CrossRef] [PubMed]

5. Farago, A.F.; Azzoli, C.G. Beyond ALK and ROS 1: RET, NTRK, EGFR and BRAF gene rearrangements in non-small cell lung cancer. Transl. Lung Cancer Res. 2017, 6, 550-559. [CrossRef]

6. Osmani, L.; Askin, F.; Gabrielson, E.; Li, Q.K. Current WHO guidelines and the critical role of immunohistochemical markers in the subclassification of non-small cell lung carcinoma (NSCLC). Moving from targeted therapy to immunotherapy. Semin. Cancer Biol. 2018, 52 Pt 1, 103-109. [CrossRef]

7. Wu, Y.L.; Planchard, D.; Lu, S.; Sun, H.; Yamamoto, N.; Kim, D.W.; Tan, D.S.W.; Yang, Y.C.; Azrif, M.; Mitsudomi, T.; et al. Pan-Asian adapted clinical practice guidelines for the management of patients with metastatic non-small-cell lung cancer: A CSCO-ESMO initiative endorsed by JSMO, KSMO, MOS, SSO and TOS. Ann. Oncol. 2019, 30, 171-210. [CrossRef] [PubMed]

8. Adjei, A.A. Pharmacology and mechanism of action of pemetrexed. Clin. Lung Cancer 2004, 5 (Suppl. 2), S51-S55. [CrossRef]

9. Scagliotti, G.V.; Parikh, P.; von Pawel, J.; Biesma, B.; Vansteenkiste, J.; Manegold, C.; Serwatowski, P.; Gatzmeier, U.; Digumarti, R.; Zukin, M.; et al. Phase III study comparing cisplatin plus gemcitabine with cisplatin plus pemetrexed in chemotherapy-naïve patients with advanced-stage non-small-cell lung cancer. J. Clin. Oncol. 2008, 26, 3543-3551. [CrossRef]

10. Paz-Ares, L.G.; de Marinis, F.; Dediu, M.; Thomas, M.; Pujol, J.L.; Bidoli, P.; Molinier, O.; Sahoo, T.P.; Laack, E.; Reck, M.; et al. PARAMOUNT: Final overall survival results of the phase III study of maintenance pemetrexed versus placebo immediately after induction treatment with pemetrexed plus cisplatin for advanced non-squamous non-small cell lung cancer. J. Clin. Oncol. 2013, 31, 2895-2902. [CrossRef] [PubMed]

11. Ciuleanu, T.; Brodowicz, T.; Zielinski, C.; Kim, J.H.; Krzakowski, M.; Laack, E.; Wu, Y.L.; Bover, I.; Begbie, S.; Tzekova, V.; et al. Maintenance pemetrexed plus best supportive care versus placebo plus best supportive care for non-small-cell lung cancer: A randomised, double-blind, phase 3 study. Lancet 2009, 374, 1432-1440. [CrossRef]

12. Hanna, N.; Shepherd, F.A.; Fossella, F.V.; Pereira, J.R.; de Marinis, F.; von Pawel, J.; Gatzemeier, U.; Tsao, T.C.; Pless, M.; Muller, T.; et al. Randomized phase III trial of pemetrexed versus docetaxel in patients with non-small-cell lung cancer previously treated with chemotherapy. J. Clin. Oncol. 2004, 22, 1589-1597. [CrossRef]

13. Ceppi, P.; Volante, M.; Saviozzi, S.; Rapa, I.; Novello, S.; Cambieri, A.; Lo Iacono, M.; Cappia, S.; Papotti, M.; Scagliotti, G.V. Squamous cell carcinoma of the lung compared with other histotypes shows higher messenger RNA and protein levels for thymidylate synthase. Cancer 2006, 107, 1589-1596. [CrossRef] [PubMed]

14. Sigmond, J.; Backus, H.H.; Wouters, D.; Temmink, O.H.; Jansen, G.; Peters, G.J. Induction of resistance to the multitargeted antifolate pemetrexed (Alimta) in WiDr human colon cancer cells is associated with thymidylate synthase overexpression. Biochem. Pharmacol. 2003, 66, 431-438. [CrossRef]

15. Giovannetti, E.; Mey, V.; Pasqualetti, G.; Marini, L.; del Tacca, M.; Danesi, R. Cellular and pharmacogenetics foundation of synergistic interaction of pemetrexed and gemcitabine in human non-small-cell lung cancer cells. Mol. Pharmacol. 2005, 68, 110-118. [CrossRef] [PubMed]

16. Sun, J.M.; Ahn, J.S.; Jung, S.H.; Sun, J.; Ha, S.Y.; Han, J.; Park, K.; Ahn, M.J. Pemetrexed plus cisplatin versus gemcitabine plus cisplatin according to thymidylate synthase expression in nonsquamous non-small-cell lung cancer: A biomarker-stratified randomized phase II trial. J. Clin. Oncol. 2015, 33, 2450-2456. [CrossRef] [PubMed]

17. Ren, S.; Chen, X.; Kuang, P.; Zheng, L.; Su, C.; Li, J.; Li, B.; Wang, Y.; Liu, L.; Hu, Q.; et al. Association of EGFR mutation or ALK rearrangement with expression of DNA repair and synthesis genes in never-smoker women with pulmonary adenocarcinoma. Cancer 2012, 118, 5588-5594. [CrossRef] [PubMed]

18. Jiang, X.; Yang, B.; Lu, J.; Zhan, Z.; Li, K.; Ren, X. Pemetrexed-based chemotherapy in advanced lung adenocarcinoma patients with different EGFR genotypes. Tumor Biol. 2015, 36, 861-869. [CrossRef]

19. Kaneda, T.; Yoshioka, H.; Tamiya, M.; Tamiya, A.; Hata, A.; Okada, A.; Niwa, T.; Shiroyama, T.; Kanazu, M.; Ishida, T.; et al. Differential efficacy of cisplatin plus pemetrexed between 1858R and Del-19 in advanced EGFR-mutant non-squamous non-small cell lung cancer. BMC Cancer 2018, 18, 1-8. [CrossRef] 
20. Noronha, V.; Patil, V.; Joshi, A.; Chougule, A.; Bhattacharjee, A.; Kumar, R.; More, S.; Goud, S.; Karpe, A.; Ramaswamy, A.; et al. Impact of exon 19 versus exon 21 EGFR-activating mutation on outcomes with upfront pemetrexed-carboplatin chemotherapy. Ecancermedicalscience 2017, 11, 776. [CrossRef]

21. Patil, V.M.; Noronha, V.; Joshi, A.; Chougule, A.B.; Bhattacharjee, A.; Kumar, R.; Goud, S.; More, S.; Ramaswamy, A.; Karpe, A.; et al. Phase III study of gefitinib or pemetrexed with carboplatin in EGFR-mutated advanced lung adenocarcinoma. ESMO Open 2017, 2, e000168. [CrossRef]

22. Sequist, L.V.; Yang, J.C.; Yamamoto, N.; O’Byrne, K.; Hirsh, V.; Mok, T.; Geater, S.L.; Orlov, S.; Tsai, C.M.; Boyer, M.; et al. Phase III study of afatinib or cisplatin plus pemetrexed in patients with metastatic lung adenocarcinoma with EGFR mutations. J. Clin. Oncol. 2013, 31, 3327-3334. [CrossRef]

23. Yang, J.C.; Wu, Y.L.; Schuler, M.; Sebastian, M.; Popat, S.; Yamamoto, N.; Zhou, C.; Hu, C.P.; O’Byrne, K.; Feng, J.; et al. Afatinib versus cisplatin-based chemotherapy for EGFR mutation-positive lung adenocarcinoma (LUX-Lung 3 and LUX-Lung 6): Analysis of overall survival data from two randomised, phase 3 trials. Lancet Oncol. 2015, 16, 141-151. [CrossRef]

24. Kato, T.; Yoshioka, H.; Okamoto, I.; Yokoyama, A.; Hida, T.; Seto, T.; Kiura, K.; Massey, D.; Seki, Y.; Yamamoto, N. Afatinib versus cisplatin plus pemetrexed in Japanese patients with advanced non-small cell lung cancer harboring activating EGFR mutations: Subgroup analysis of LUX-Lung 3. Cancer Sci. 2015, 106, 1202-1211. [CrossRef]

25. Cheng, Y.; Murakami, H.; Yang, P.C.; He, J.; Nakagawa, K.; Kang, J.H.; Kim, J.H.; Wang, X.; Enatsu, S.; Puri, T.; et al. Randomized phase II trial of gefitinib with and without pemetrexed as first-line therapy in patients with advanced nonsquamous non-small-cell lung cancer with activating epidermal growth factor receptor mutations. J. Clin. Oncol. 2016, 34, 3258-3266. [CrossRef] [PubMed]

26. Yang, J.C.H.; Cheng, Y.; Murakami, H.; Yang, P.C.; He, J.; Nakagawa, K.; Kang, J.H.; Kim, J.H.; Hozak, R.R.; Nguyen, T.S.; et al. A randomized phase 2 study of gefitinib with or without pemetrexed as first-line treatment in nonsquamous non-small cell lung cancer with EGFR mutation: Final overall survival and biomarker analysis. J. Thorac. Oncol. 2020, 15, 91-100. [CrossRef] [PubMed]

27. Seike, M.; Inoue, A.; Sugawara, S.; Morita, S.; Hosomi, Y.; Okeda, S.; Watanabe, K.; Takahashi, K.; Fujita, Y.; Harada, T.; et al. Phase III study of gefitinib (G) versus gefitinib+carboplatin+pemetrexed (GCP) as 1st-line treatment for patients (pts) with advanced non-small cell lung cancer. Ann. Oncol. 2018, 29 (Suppl. 8), viii493-viii547. [CrossRef]

28. Noronha, V.; Patil, V.M.; Joshi, A.; Menon, N.; Chougule, A.; Mahajan, A.; Janu, A.; Purandare, N.; Kumar, R.; More, S.; et al. Gefitinib versus gefitinib plus pemetrexed and carboplatin chemotherapy in patients EGFR-mutated lung cancer. J. Clin. Oncol. 2020, 38, 124-136. [CrossRef] [PubMed]

29. Wu, S.G.; Yang, C.H.; Yu, C.J.; Lee, J.H.; Hsu, Y.C.; Chang, Y.L.; Shih, J.Y.; Yang, P.C. Good response to pemetrexed in patients of lung adenocarcinoma with epidermal growth factor receptor (EGFR) mutations. Lung Cancer 2011, 72, 333-339. [CrossRef]

30. Joshi, A.; Noronha, V.; Patil, V.M.; Chougule, A.; Bhattacharjee, A.; Kumar, R.; Goud, S.; More, S.; Ramaswamy, A.; Karpe, A.; et al. Efficacy of second-line pemetrexed-carboplatin in EGFR-activating mutation-positive NSCLC: Does exon 19 deletion differ from exon 21 mutation. Chemother. Res. Pract. 2017, 2017. [CrossRef] [PubMed]

31. Soria, J.C.; Wu, Y.L.; Nakagawa, K.; Kim, S.W.; Yang, J.J.; Ahn, M.J.; Wang, J.; Yang, J.C.; Lu, Y.; Atagi, S.; et al. Gefitinib plus chemotherapy versus placebo plus chemotherapy in EGFR-mutation-positive non-small-cell lung cancer after progression on first-line gefitinib (IMPRESS): A phase 3 randomised trial. Lancet Oncol. 2015, 16, 990-998. [CrossRef]

32. Mok, T.S.K.; Kim, S.W.; Wu, Y.L.; Nakagawa, K.; Yang, J.J.; Ahn, M.J.; Wang, J.; Yang, J.C.; Lu, Y.; Atagi, S.; et al. Gefitinib plus chemotherapy versus chemotherapy in epidermal growth factor receptor mutation-positive non-small-cell lung cancer resistant to first-line gefitinib (IMPRESS): Overall survival and biomarker analysis. J. Clin. Oncol. 2017, 35, 4027-4034. [CrossRef]

33. Han, B.; Yang, L.; Wang, X.; Yao, L. Efficacy of pemetrexed-based regimens in advanced non-small cell lung cancer patients with activating epidermal growth factor receptor mutations after tyrosine kinase inhibitor failure: A systematic review. OncoTargets Ther. 2018, 11, 2121-2129. [CrossRef] 
34. Yang, C.J.; Tsai, M.J.; Hung, J.Y.; Liu, T.C.; Chou, S.H.; Lee, J.Y.; Hsu, J.S.; Tsai, Y.M.; Huang, M.S.; Chong, I.W. Pemetrexed had significantly better clinical efficacy in patients with stage IV lung adenocarcinoma with susceptible EGFR mutations receiving platinum-based chemotherapy after developing resistance to the first-line gefitinib treatment. OncoTargets Ther. 2016, 9, 1579-1587. [CrossRef] [PubMed]

35. Mok, T.S.; Wu, Y.L.; Ahn, M.J.; Garassino, M.C.; Kim, H.R.; Ramalingam, S.S.; Shepher, F.A.; He, Y.; Akamatsu, H.; Theelen, W.S.; et al. Osimertinib or platinum-pemetrexed in EGFR T790M-positive lung cancer. N. Engl. J. Med. 2017, 376, 629-640. [CrossRef]

36. Ma, D.; Hao, X.; Wang, Y.; Xing, P.; Li, J. Clinical effect of pemetrexed as the first-line treatment in Chinese patients with advanced anaplastic lymphoma kinase-positive non-small cell lung cancer. Thorac. Cancer 2016, 7, 452-458. [CrossRef]

37. Shaw, A.T.; Varghese, A.M.; Solomon, B.J.; Costa, D.B.; Novello, S.; Mino-Kenudson, M.; Awad, M.M.; Engelman, J.A.; Riely, G.J.; Monica, V.; et al. Pemetrexed-based chemotherapy in patients with advanced, ALK-positive non-small cell lung cancer. Ann. Oncol. 2013, 24, 59-66. [CrossRef] [PubMed]

38. Park, S.; Park, T.S.; Choi, C.M.; Lee, D.H.; Kim, S.W.; Lee, J.S.; Kim, W.S.; Song, J.S.; Lee, J.C. Survival benefit of pemetrexed in lung adenocarcinoma patients with anaplastic lymphoma kinase gene rearrangements. Clin. Lung Cancer 2015, 16, e83-e89. [CrossRef] [PubMed]

39. Jo, J.; Kim, S.H.; Kim, Y.J.; Lee, J.; Kim, M.; Keam, B.; Kim, T.M.; Heo, D.S.; Chung, J.H.; Jeon, Y.K.; et al. Efficacy of pemetrexed-based chemotherapy in comparison to non-pemetrexed-based chemotherapy in advanced, ALK+ non-small cell lung cancer. Yonsei Med. J. 2018, 59, 202-210. [CrossRef] [PubMed]

40. Solomon, B.J.; Mok, T.; Kim, D.W.; Wu, Y.L.; Nakagawa, K.; Mekhail, T.; Felip, E.; Cappuzzo, F.; Paolini, J.; Usari, T.; et al. First-line crizotinib versus chemotherapy in ALK-positive lung cancer. N. Engl. J. Med. 2014, 371, 2167-2177. [CrossRef]

41. Soria, J.C.; Tan, D.S.W.; Chiari, R.; Wu, Y.L.; Paz-Ares, L.; Wolf, J.; Geater, S.L.; Orlov, S.; Cortinovis, D.; $\mathrm{Yu}, \mathrm{C} . J . ;$ et al. First-line ceritinib versus platinum-based chemotherapy in advanced ALK-rearranged non-small-cell lung cancer (ASCEND-4): A randomised, open-label, phase 3 study. Lancet 2017, 389, 917-929. [CrossRef]

42. Lee, J.O.; Kim, T.M.; Lee, S.H.; Kim, D.W.; Kim, S.; Jeon, Y.K.; Chung, D.H.; Kim, W.H.; Kim, Y.T.; Yang, S.C.; et al. Anaplastic lymphoma kinase translocation: A predictive biomarker of pemetrexed in patients with non-small cell lung cancer. J. Thorac. Oncol. 2011, 6, 1474-1480. [CrossRef]

43. Shaw, A.T.; Kim, D.W.; Nakagawa, K.; Seto, T.; Crinó, L.; Ahn, M.J.; de Pas, T.; Besse, B.; Solomon, B.J.; Blackhall, F.; et al. Crizotinib versus chemotherapy in advanced ALK-positive lung cancer. N. Engl. J. Med. 2013, 368, 2385-2394. [CrossRef] [PubMed]

44. Camidge, D.R.; Kono, S.A.; Lu, X.; Okuyama, S.; Barón, A.E.; Oton, A.B.; Davies, A.M.; Varella-Garcia, M.; Franklin, W.; Doebele, R.C. Anaplastic lymphoma kinase gene rearrangements in non-small cell lung cancer are associated with prolonged progression-free survival on pemetrexed. J. Thorac. Oncol. 2011, 6, 774-780. [CrossRef] [PubMed]

45. Song, Z.; Su, H.; Zhang, Y. Patients with ROS1 rearrangement positive non-small cell lung cancer benefit from pemetrexed-based chemotherapy. Cancer Med. 2016, 5, 2688-2693. [CrossRef] [PubMed]

46. Kim, H.R.; Lim, S.M.; Kim, H.J.; Hwang, S.K.; Park, J.K.; Shin, E.; Bae, M.K.; Ou, S.H.; Wang, J.; Jewell, S.S.; et al. The frequency and impact of ROS1 rearrangement on clinical outcomes in never smokers with lung adenocarcinoma. Ann. Oncol. 2013, 24, 2364-2370. [CrossRef] [PubMed]

47. Chen, Y.F.; Hsieh, M.S.; Wu, S.G.; Chang, Y.L.; Yu, C.J.; Yang, J.C.; Yang, P.C.; Shih, J.Y. Efficacy of pemetrexed-based chemotherapy in patients with RIS1 fusion-positive lung adenocarcinoma compared with patients harboring other driver mutations in East Asian populations. J. Thorac. Oncol. 2016, 11, 1140-1152. [CrossRef]

48. Song, Z.; Yu, X.; Zhang, Y. Clinicopathologic characteristics, genetic variability and therapeutic options of RET rearrangements patients in lung adenocarcinoma. Lung Cancer 2016, 101, 16-21. [CrossRef] [PubMed]

49. Shen, T.; Pu, X.; Wang, L.; Yu, Z.; Li, J.; Zhang, Y.; Chan, H.; Xu, C.; Song, Z.; Wang, W. Association between RET fusions and efficacy of pemetrexed-based chemotherapy for patients with advanced NSCLC in China: A multicenter retrospective study. Clin. Lung Cancer 2020, in press. [CrossRef]

50. Drilon, A.; Bergagnini, I.; Delasos, L.; Sabari, J.; Woo, K.M.; Plodkowski, A.; Wang, L.; Hellmann, M.D.; Joubert, P.; Sima, C.S.; et al. Clinical outcomes with pemetrexed-based systemic therapies in RET-rearranged lung cancers. Ann. Oncol. 2016, 27, 1286-1291. [CrossRef] 
51. Wang, Y.; Zhang, S.; Wu, F.; Zhao, J.; Li, X.; Zhao, C.; Ren, S.; Zhou, C. Outcomes of pemetrexed-based chemotherapies in HER2-mutant lung cancers. BMC Cancer 2018, 18, 326. [CrossRef]

52. Eng, J.; Hsu, M.; Chaft, J.E.; Kris, M.G.; Arcila, M.E.; Li, B.T. Outcomes of chemotherapies and HER2 directed therapies in advanced HER2-mutant lung cancers. Lung Cancer 2016, 99, 53-56. [CrossRef]

53. Gow, C.H.; Chang, H.T.; Lim, C.K.; Liu, C.Y.; Chen, J.S.; Shih, J.Y. Comparable clinical outcomes in patients with HER2-mutant and EGFR-mutant lung adenocarcinomas. Genes Chromosom. Cancer 2017, 56, 373-381. [CrossRef]

54. Gandara, D.R.; Leighl, N.; Delord, J.P.; Barlesi, F.; Bennouna, J.; Zalcman, G.; Infante, J.R.; Reckamp, K.L.; Kelly, K.; Shepherd, F.A.; et al. A phase 1/1b study evaluating trametinib plus docetaxel or pemetrexed in patients with advanced non-small cell lung cancer. J. Thorac. Oncol. 2017, 12, 556-566. [CrossRef]

55. Wakelee, H.; Zvirbule, Z.; de Braud, F.; Kingsley, C.D.; Mekhail, T.; Lowe, T.; Schütte, W.; Lena, H.; Lawler, W.; Braiteh, F.; et al. Efficacy and safety of onartuzumab in combination with first-line bevacizumabor pemetrexed-based chemotherapy regimens in advanced non-squamous, non-small-cell lung cancer. Clin. Lung Cancer 2017, 18, 50-59. [CrossRef] [PubMed]

56. Postmus, P.E.; Kerr, K.M.; Oudkerk, M.; Senan, S.; Waller, D.A.; Vansteenkiste, J.; Escriu, C.; Peters, S.; ESMO Guidelines Committee. Early and locally advanced non-small-cell lung cancer (NSCLC): ESMO clinical practice guidelines for diagnosis, treatment and follow-up. Ann. Oncol. 2017, 28 (Suppl. 4), iv1-iv21. [CrossRef] [PubMed]

57. Hanna, N.; Johnson, D.; Temin, S.; Baker, S., Jr.; Brahmer, J.; Ellis, P.M.; Giaccone, G.; Hesketh, P.J.; Jaiyesimi, I.; Leighl, N.B.; et al. Systemic therapy for stage IV non-small-cell lung cancer: American Society of Clinical Oncology Clinical Practice Guideline update. J. Clin. Oncol. 2017, 35, 3484-3515. [CrossRef] [PubMed]

58. Jänne, P.; Planchard, D.; Howarth, P.; Todd, A.; Kobayashi, K. Osimertinib plus platinum/pemetrexed in newly-diagnosed advanced EGFRm-positive NSCLC; the phase 3 FLAURA2 study. J. Thorac. Oncol. 2019, 14, S222. [CrossRef]

59. Yu, H.A.; Arcila, M.E.; Rekhtman, N.; Sima, C.S.; Zakowski, M.F.; Pao, W.; Kris, M.G.; Miller, V.A.; Ladanyi, M.; Riely, G.J. Analysis of tumor specimens at the time of acquired resistance to EGFR-TKI therapy in 155 patients with EGFR-mutant lung cancers. Clin. Cancer Res. 2013, 19, 2240-2247. [CrossRef]

60. Dagogo-Jack, I.; Shaw, A.T. Tumour heterogeneity and resistance to cancer therapies. Nat. Rev. Clin. Oncol. 2018, 15, 81-94. [CrossRef]

61. Borghaei, H.; Paz-Ares, L.; Horn, L.; Spigel, D.R.; Steins, M.; Ready, N.E.; Chow, L.Q.; Vokes, E.E.; Felip, E.; Holgado, E.; et al. Nivolumab versus docetaxel in advanced nonsquamous non-small-cell lung cancer. N. Engl. J. Med. 2015, 373, 1627-1639. [CrossRef]

62. Herbst, R.S.; Baas, P.; Kim, D.W.; Felip, E.; Pérez-Gracia, J.L.; Han, J.Y.; Molina, J.; Kim, J.H.; Dubos Arvis, C.; Ahn, M.J.; et al. Pembrolizumab versus docetaxel for previously treated, PD-L1-positive, advanced non-small-cell lung cancer (KEYNOTE-010): A randomised controlled trial. Lancet 2016, 387, 1540-1550. [CrossRef]

63. Fehrenbacher, L.; Spira, A.; Ballinger, M.; Kowanetz, M.; Vansteenkiste, J.; Mazieres, J.; Park, K.; Smith, D.; Artal-Cortes, A.; Lewanski, C.; et al. Atezolizumab versus docetaxel for patients with previously treated non-small-cell lung cancer (POPLAR): A multicentre, open-label, phase 2 randomised controlled trial. Lancet 2016, 387, 1837-1846. [CrossRef]

64. Rittmeyer, A.; Barlesi, F.; Waterkamp, D.; Park, K.; Ciardiello, F.; von Pawel, J.; Gadgeel, S.M.; Hida, T.; Kowalski, D.M.; Cobo Dols, M.; et al. Atezolizumab versus docetaxel in patients with previously treated non-small-cell lung cancer (OAK): A phase 3, open-label, multicentre randomised controlled trial. Lancet 2017, 389, 255-265. [CrossRef]

65. Melosky, B.; Juergens, R.; Hirsh, V.; McLeod, D.; Leighl, N.; Tsao, M.S.; Card, P.B.; Chu, Q. Amplifying outcomes: Checkpoint inhibitor combinations in first-line non-small cell lung cancer. Oncologist 2020, 25, 64-77. [CrossRef]

66. Nakagawa, K.; Yang, J.C.H.; Park, K.; Ohe, Y.; Wu, Y.; Gainor, J.; Blackwood-Chirchir, A.; Yang, R.; Chang, I.; Mok, T. Checkmate 722: A phase 3 trial of nivolumab with chemotherapy or ipilimumab vs chemotherapy in epidermal growth factor receptor (EGFR)-mutation, T790M-negative stage IV or recurrent non-small cell lung cancer (NSCLC) after EGFR tyrosine kinase inhibitor (TKI) therapy. Ann Oncol. 2016, 27 (Suppl. 9), ix139-ix156. [CrossRef] 
67. Hayashi, H.; Chiba, Y.; Sakai, K.; Fujita, T.; Yoshioka, H.; Sakai, D.; Kitagawa, C.; Naito, T.; Takeda, K.; Okamoto, I.; et al. A randomized phase II study comparing nivolumab with carboplatin-pemetrexed for patients with EGFR mutation-positive nonsquamous non-small-cell lung cancer who acquire resistance to tyrosine kinase inhibitors not due to a secondary T790M mutation: Rationale and protocol design for the WJOG8515L study. Clin Lung Cancer. 2017, 18, 719-723. [CrossRef] [PubMed]

68. Riely, G.; Hui, R.; Carbone, D.; Park, K.; Carrigan, M.; Xu, X.; Dang, T.; Yang, J.C.H. Phase 3 study of pemetrexed-platinum with or without pembrolizumab for TKI-resistant/EGFR-mutated advanced NSCLC: KEYNOTE-789. J Thorac Oncol. 2018, 13, S494. [CrossRef]

(C) 2020 by the authors. Licensee MDPI, Basel, Switzerland. This article is an open access article distributed under the terms and conditions of the Creative Commons Attribution (CC BY) license (http://creativecommons.org/licenses/by/4.0/). 